\title{
The Vapour Phase Soldering (VPS) technology: A review
}

\author{
Balázs Illés ${ }^{1}$, Attila Géczy ${ }^{1}$, Gábor Harsányi ${ }^{1}$ \\ ${ }^{1}$ Department of Electronics Technology, Budapest University of Technology and Economics, \\ Egry József u. 18, Budapest, Hungary, \\ billes@ett.bme.hu
}

\begin{abstract}
:
Purpose: This paper presents a review of the recent developments about the vapour phase soldering technology. This study focuses on the fallowing topics: recent developments of the technology (like soft and vacuum vapour phase soldering); measurement and characterization methods of vapour space (temperature and pressure); numerical simulation of the VPS soldering process (like condensate layer and solder joint formation); and quality and reliability studies of the solder joints prepared by VPS (like void content and microstructure of the solder joints).
\end{abstract}

Design/methodology/approach: This study was written according to the results of a worldwide literature review about the substantial previous works in the past decade and according to the own results and experiences of authors from around the globe.

Findings: Up to now, a part of the electronics industry believes that the reflow soldering with VPS method is a significant alternative of convection and infrared technologies. The summarized results of the field in this study supports this idea.

Research limitations/implications: This literature review provides engineers and researchers with understanding the limitations and application possibilities of the VPS technology and the current challenges in soldering technology.

Originality/value: Our paper summarizes the most important advantages of VPS technology compared to the other reflow soldering methods as well as points out the necessary further developments and possible research directions

Keywords: reflow soldering; VPS; numerical simulation; solder joint quality and reliability; measurement

\section{INTRODUCTION}

The condensation phenomenon is widely used in the everyday life for heating or cooling. The condensation can ensure very high heat transfer (compared to the other technologies like convection or heat radiation), therefore it is used for building heating with heat pump technology (Naldi and Zanchini, 2017); for refrigerator cooling with hydro- 
chlorofluorocarbons (HFC) refrigerants (Kaew-On et al., 2016); and for microelectronics heat pipes (Chang and Hung, 2017), etc. Vapour Phase Soldering (VPS) - or in other words Condensation Soldering - is an alternative for conventional soldering technologies. This reflow type soldering method can substitute infrared or convection type reflow principles in given cases.

The technology sequence of the reflow soldering process is the following: the solder paste is deposited onto the solder pads of the Printed Circuit Board (PCB) (Fig. 1a)) using a stencil printer (Fig. 1b)). The Surface Mount Devices (SMDs) are placed onto the solder paste (Fig. 1. c)) by a component placement machine. As the final step of the technology, the whole assembly is heated up over the melting point of the solder, which will melt and form the solder joints between the leads of the SMDs and the pads of the PCB.

In the VPS technology, condensation heating is used for reflow soldering. The working principle is the following: a heat transfer fluid is boiled and evaporated in a closed tank. The evaporated heat transfer liquid forms a vapour space (Fig. 1d), which works as the heat transfer agent, in which the soldered assembly is immersed (Fig. 1e). The vapour condensates on the colder surface of the assembly and forms a condensate layer. This layer transfers the latent heat of condensation and the conducted heat from the vapour into the assembly. The assembly is warmed up to the boiling point of the heat transfer liquid. After the solder melts and wets the solder pads, the assembly is lifted out from the vapour space in order to cool down and to solidify the solder joints (Fig. 1f)).

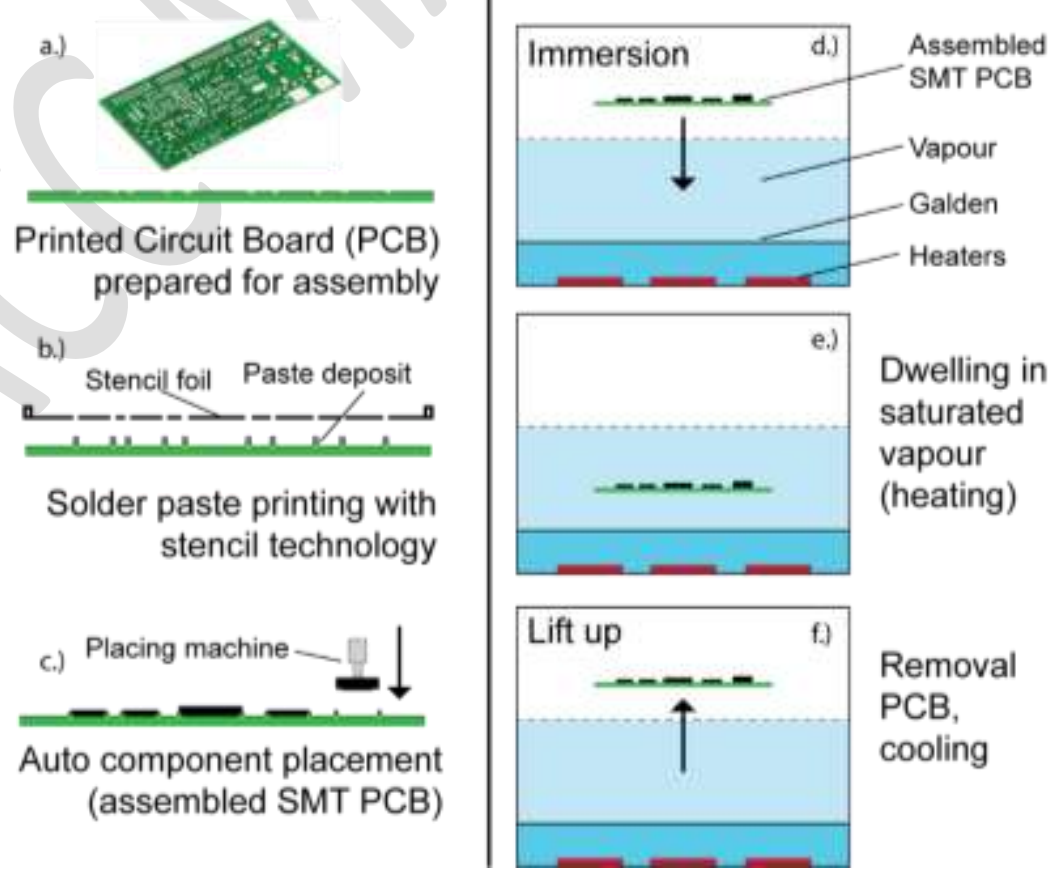

Fig. 1. The reflow soldering technology and the VPS process (Illés et al., 2017A). 
The VPS is not a newly developed soldering method; it was invented by (Pfahl and Ammann, 1975) in the 70's. The process and the appliances were then constantly improved later by (Wenger and Mahajan, 1981). In the past, the biggest concern about the VPS process was the use of harmful chemicals as heat transfer liquid, due to excessive chlorofluorocarbon (CFC) gas emission the technology was even banned for a while. VPS got renewed attention with the introduction of Galden fluid, which is Perfluoropolyether, PFPE. The Galden contains ether chains closed with carbon-fluorine bonds (Perfluoropolyether, PFPE) (Eq. 1). The boiling point of the Galden liquid can be set with the length of the ether chain between 150 and $260{ }^{\circ} \mathrm{C}$ (Nielsen et al., 2015).

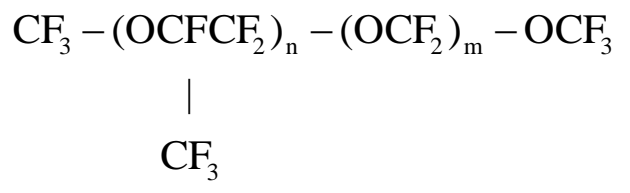

Galden is also considered as a harmless, inert material, which is noncorrosive, nontoxic, nonflammable (Sprovieri, 2012), it has has zero ozone depletion potential (Zero ODP), and it is used in many other industrial applications for heat transfer (HT type Galden fluids), semiconductor cleaning (SV type Galden fluid) or testing and hermetic sealing (D02 type fluid). VPS now is also considered as an environmentally friendly solution for reflow soldering, while it is efficient from the point of energy consumption, and the applied chemical (the Galden) is harmless and environmental friendly.

The main advantages of the VPS process (compared to the regular reflow soldering technologies) are the uniform heating of the soldered assembly where the temperature is limited to the boling point of the Galden liquid (Huang and Zhang, 2015); the inert atmosphere (fluxes with lower activation level can be used (Coombs and Freedman, 2008) and the condensed film layer keeping the oxygen and other gases from direct contact of the solder paste; and the lack of shadowing effect of larger components on small ones (Illés and Bakó, 2014). Since the condensation has around 2-3 times higher heat transfer coefficient than forced convection, considerable disadvantage is the rapid heating, which may cause damage in the solder assembly (popcorn effect, and delamination of plastic packaging (Lee and Earmme, 1998). In addition, the closed working zone has also a disadvantage, since the condensation layer can trap the flux gases inside the solder joint which can cause voiding and paste sputtering (Synkiewicz et al., 2014). Furthermore, the increased wettability in the inert atmosphere may result in more frequent tombstoning than at the conventional reflow soldering technologies (Dušek et al., 2018).

VPS technology proved that it is suitable for special soldering applications. VPS was successfully applied for PoP (Package on Package (Coada, 2009)) and 3D PCB assemblies 
(Nowottnick and Diehm, 2007). VPS was used for fine-pitch components (Géczy, et al., 2010) as well as for experimental bumping (Bátorfi et al., 2010). Good results were achieved during the soldering on special substrates such as glass- and metal (aluminum) core substrates (Plotog et al. 2008), biodegradable biopolymers (Géczy et al., 2011) and on DBC (Skwarek et al., 2015). VPS can be used for Pin-in-Paste (PIP) technology (Bielick et al., 2010) and rework of large sized SMD components with high thermal capacity (such as power components and connectors) (Bielick, 2010). In the past decade, several researches were performed to find the possibilities and limitations of this promising technology. The present work summarizes the most important findings about VPS technology compared to the other soldering methods as well as points out the necessary further developments.

\section{RESULTS}

During the preparation of the literature review, we collected the existing results about the VPS technology around four key topics, which are the following: technology development of the VPS; measurement and characterization methods of the VPS; numerical simulation of the VPS; quality and reliability of the solder joints prepared by VPS.

\subsection{Recent technological developments of the VPS technology}

The VPS technology can be implemented in batch type (Vianco, 1999) or inline type (Lee, 2002) VPS soldering station constructions. The basic VPS solution uses saturated vapour for heat transfer. More modern VPS stations adjusts vapor level inside the soldering chamber with controlled power on the heating. Linear thermal profiles can be achieved with VPS, where the gradients can be adjusted with the heating power (Duck and Zabel, 2010). To improve the soldering quality and reduce the number of the failures, several modifications were added to the process and the soldering stations themselves.

Paste spluttering, tombstoning, and damaged components can be avoided and non-linear soldering profile can be formed with the application of preheating (Dušek et al., 2018), and the dwell time in the vapour can be reduced. Preheating was first used in batch type stations with an additional secondary vapour blanket or with infrared radiators in a separated preheating zone (Vianco, 1999). Nowadays different solutions are available for profile customizations without any additional preheating zone. The simplest solution is the additional cooling pipes at the middle of the process zone around the soldered assembly (Duck and Zabel, 2010). The most novel methods in order to reach non-linear thermal profile is the application of non-saturated vapour space by the Heat Level (HL) or by the soft VPS (SVP) methods (Géczy, 2014). Nonsaturated vapour space means that the vapour concentration has a gradient in the process zone 
which results in a variation of the heat transfer coefficient, depending on the available vapour for condensation.

During HL method (Fig. 2 b.), the assembly is immersed over the heat transfer liquid but before the vapour space formation. In this case the generated vapour is consumed instantly by the colder assembly and coherent and dense vapour space can form only after the assembly is heated up to the boiling point of the heat transfer liquid. A temperature sensor is placed a bit above the level of the assembly, which indicates the vertical growing of the vapour space and providing real time information about the end of the process. The HL method ensures easier and more exact setting of the heating power according to the needs of the given soldered assembly (it allows to spare the energy and the expensive heat transfer liquid). In addition, the real-time controlled heating power allows creating non-linear thermal profiles; even a soak type profile can be developed which is a common requirement of modern lead-free solder pastes. The limitations of the technology are the following: soldering positions has to be set carefully and heating power has to be optimized for each assembly according to the heat capacity and the component combination.

The "soft VPS" method was developed by IBL (Leicht and Thumm, 2008), during this method the assembly is immersed into different heights of the non-saturated vapor space (Fig. $2 \mathrm{c})$. The gradient of the heating can be set with real-time controlled immersion and elevation of the soldered assembly. The soft VPS method can produce the most accurate thermal profile, which match the different requirements of the solder pastes, and avoid such soldering failures paste spluttering, tombstoning and package delamination.

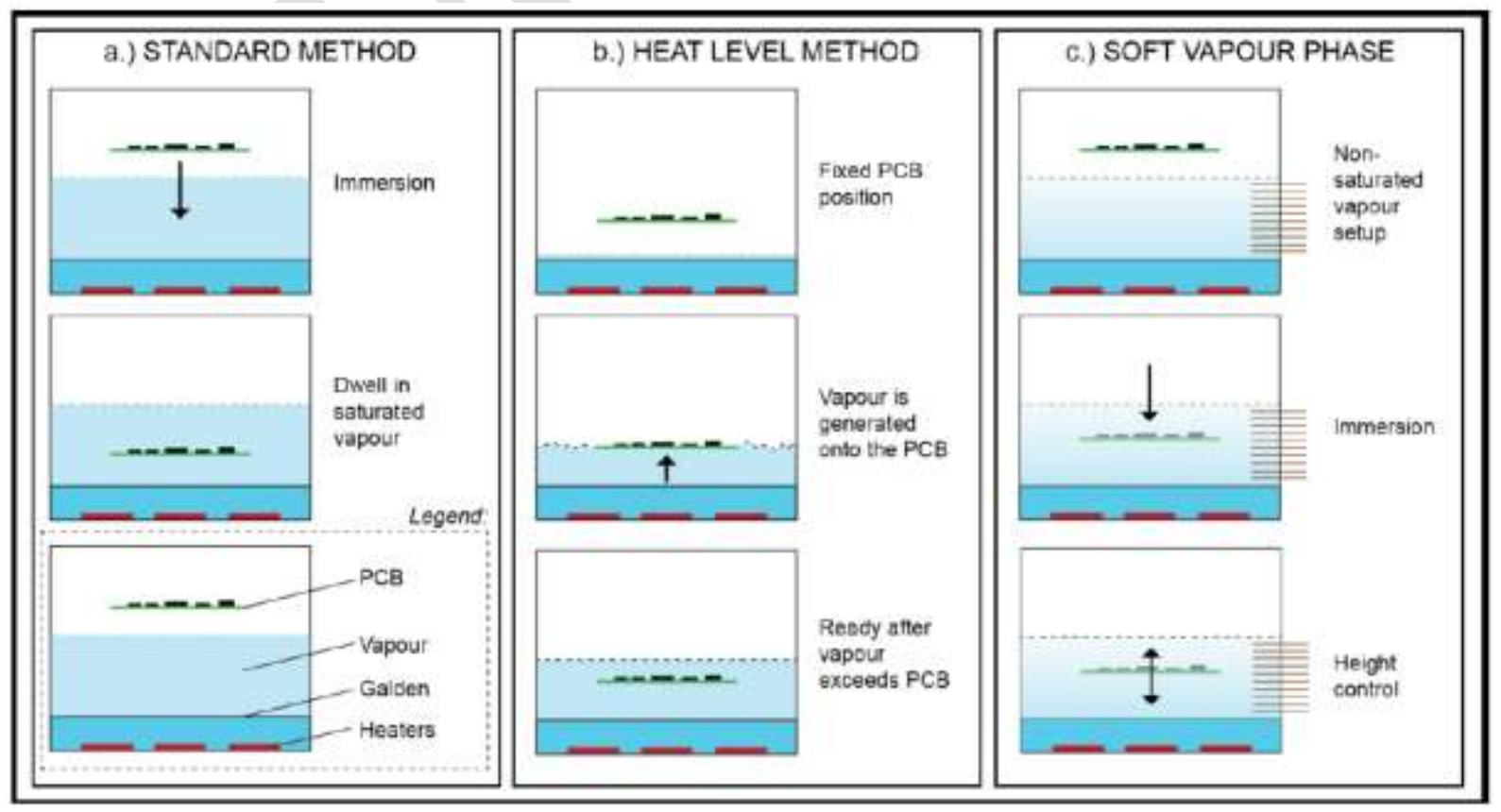

Fig. 2: Comparison of the different VPS heating methods (Géczy, 2014). 
As it was discussed, the voiding failure is generally more serious in the case of VPS than at other reflow soldering technologies (Villain et al., 2000). A solution to decrease the number of voids came from Asscon, who added a vacuum chamber to the VPS process (Zabel and Duck, 2009), where the voids are drawn out from the molten solder. The lowered pressure in the vacuum chamber is usually $\sim 10-20 \mathrm{kPa}$. According to the first results the vacuum VPS is a promising technology (Fig. 3), however the fast suctioning of the vapour can disturb the thermal processes during the soldering which might have negative effects on the solder joint formation (see in details at Section 2.4). Vacuum VPS ovens are often used in the case automotive and power electronics where large sized components with large amount of solder paste cause even more voiding problems.
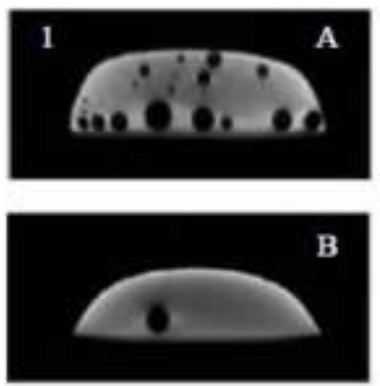
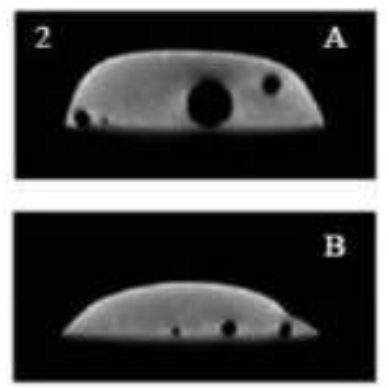
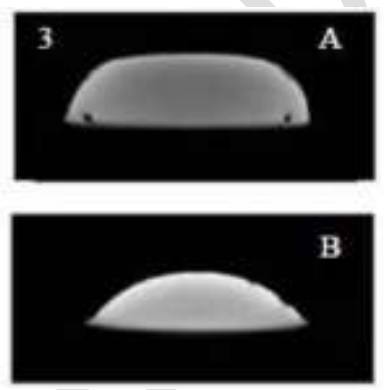
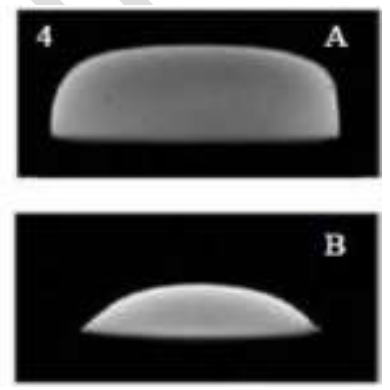

Fig. 3. Cross-section figures (by computer tomography) of voids in solder joints prepared with and without vacuum option: $\mathrm{A}, \mathrm{B}$ - corresponds to different cross section surfaces: 1 -

SAC305 without vacuum; $2-\mathrm{Pb} / \mathrm{Sn}$ without vacuum; 3 - SAC305 vacuum; $4-\mathrm{Pb} / \mathrm{Sn}$ vacuum (Synkiewicz, 2014).

\subsection{Measurement and characterization methods of the VPS technology}

As in the case of all soldering technologies, the characterization and the monitoring of the process parameters is identical to be able to control the process itself. At the VPS process, this question is even more serious because the harsh environment in the VPS process zone $\left(240^{\circ} \mathrm{C}\right.$ in a $20 \mathrm{~kg} / \mathrm{m}^{3}$ dense vapour). Besides the technical innovations - discussed in section 2.1 - there is only a few amount of researches which deals with the characterization of the VPS process.

As a heat treatment, the temperature mapping is an important aspect of the process. The most simple solution is the direct temperature measurement of the soldered assembly and the process zone by K- (Livovsky et al., 2008) or Pt-type thermocouples (Illyefalvi-Vitéz et al., 2010A). One of the key point of the accurate thermal profiling is the proper attachment of the probes to the measured object (which ensures the best "thermal connection"). Géczy et al. compared the different thermocouple settings during the VPS process and they found that open thermocouple wires should be avoided in the case of VPS technology because the uninsulated ends have 
considerable disturbing effect on the measurements. They also compared the temporary attachment methods of the thermocouples and showed that the Kapton tape is less reliable than the Alu-tape, since the condensate underflows the Kapton tape, decreases its adhesion property and the thermocouples are not fixed properly (Géczy et al., 2016).

The VPS technology offers a serious advantage, compared to the conventional reflow soldering technologies, that the thermal profile can be refined with the real-time control of the heating power of with the real-time movement of the soldered assembly in the process zone between the differently saturated vapour spaces which have different heat transfer coefficients. Livovsky and Pietrikova designed a real-time thermal profile monitoring system for such a purpose (Livovsky and Pietrikova, 2017). They found that the real-time thermal monitoring ensures that required and pre-determined thermal profile can be hold with very high accuracy $\left( \pm 2^{\circ} \mathrm{C}\right)$. In addition they verified their method with a power electronics module which has high heat capacity and large dimensions. This complicated soldering case shows even more the efficiency of their method.

In the case of such a processes which based on heat transfer, the most straight forward research step is to determine the Heat Transfer Coefficient (HTC, $\left.\left[\mathrm{W} / \mathrm{m}^{2} . \mathrm{K}\right]\right)$. In the possession of the HTC values the warming up of the soldered assembly can be calculated easily with the Newton's low:

$\dot{Q}(t)=H T C \cdot A \cdot\left(T_{f}-T_{s}\right)$

where $Q$ is the energy [J], $A$ is the area whereon the heat transfer happens $\left[\mathrm{m}^{2}\right]$ and $T$ is the temperature of the fluid and solid materials [K]. The HTC value mainly depends on the heated material and the temperature difference during the heat transfer. Fazekas et al., 2017 compared the warming up of different substrate materials (FR4, polyimide, and alumina) during the VPS process. They showed that the thermal diffusivity of the substrate material highly effects on the heat transfer. Géczy, 2017 measured the HTC values in the function of time and location on rectangular and round-shape FR4 boards during the VPS process. He showed that the HTC value is between $100-400 \mathrm{~W} / \mathrm{m}^{2} . \mathrm{K}$ and he found that the rectangular boards have non negligible corner effects on the HTC distribution with even $50-60 \mathrm{~W} / \mathrm{m}^{2} \mathrm{~K}$ differences. This corner effect is much less serious at round-shape boards, the differences are only $20-30 \mathrm{~W} / \mathrm{m}^{2} \mathrm{~K}$. He also highlighted the careful PCB and component placement design since such a high differences in the HTC value may results in tombstone failures due to the non-uniform heating.

The author proved via calculations that the differences in the HTC distribution on the substrates are caused by change of the condensate thickness on the substrate, since the heat transfer highly depends on the thermal diffusivity of the condensate layer (Illés et al., 2016). 
Moreover, they characterized the change of the HTC values on different substrate materials for the whole VPS process (Fig. 4).

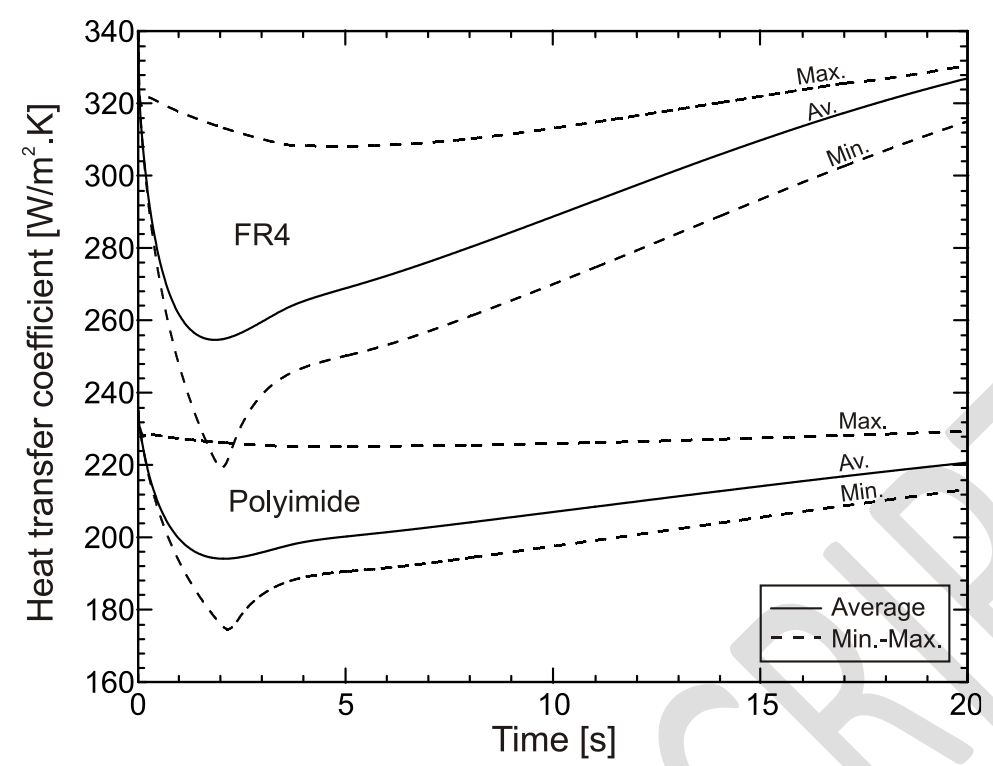

Fig. 4. HTC values on FR4 and polyimide substrates during the VPS process (Illés et al., 2016).

It is visible in Fig. 4, that the HTC values highly depends on the condensate thickness as well (on the thermal diffusivity of the condensate layer) and not only on the temperature difference, since the HTC is decreasing at the first part of the process when the condensate layer thickness is generally increasing. As the HTC distribution is not even on the substrate, Géczy et al., 2017 examined experimentally the heating of large size components at different locations on an FR4 substrate. Their main conclusion was that the thermocoupling shows heating transient differences around the large size components, but not in a clear and significant manner. The serious sensitivity of VPS process for measurements suggest to investigate the phenomenon by numerical simulations (see in section 2.3).

Another important parameter of the VPS process is the vapour concentration. First basic methods for vapour characterization were the observation the vapour saturation by floating polymer pillows (Illyefalvi-Vitéz et al., 2010B), measurement of vapour propagation and detecting the condensed droplets inside the vapour space by optical probes (Géczy et al., 2012). The obtained results were not promising since the bad visibility in the dense vapour. Géczy et $a l ., 2013 \mathrm{~A}$ invented a novel method for the characterization of the vapour spece before the soldering process. They investigated the development of the vapour space (the concentration change of the vapour) with a differential pressure sensor. They defined three stages (I, II and III) of the initial warming up of the process zone (Fig. 5) and the showed that VPS machine is ready for the soldering only after the third stage (saturated stage). 


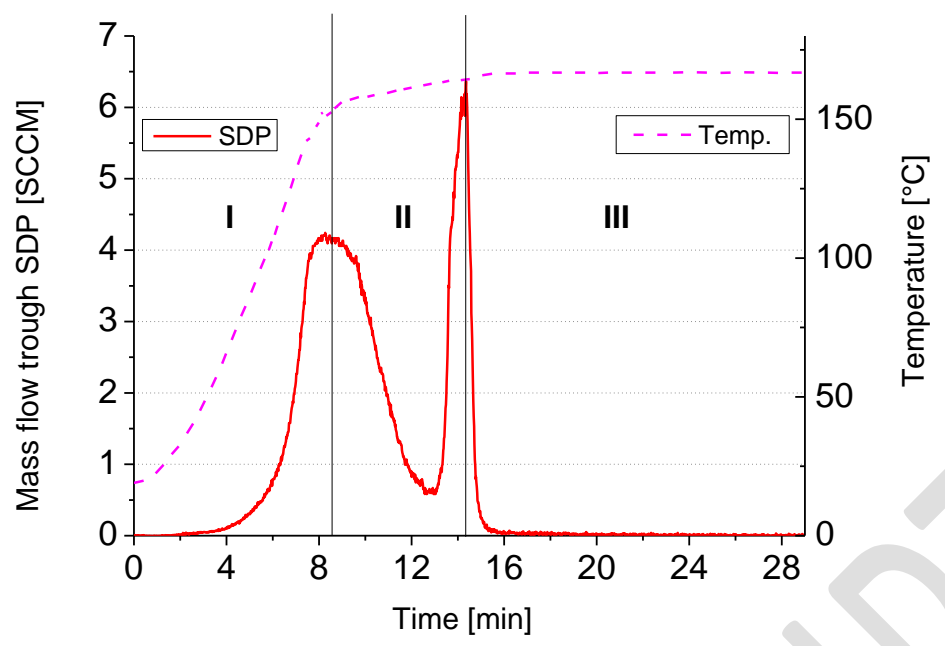

Fig. 5. Dynamic pressure measurements combined with temperature measurements; 3 different stages highlighted (I-II-III) (Géczy et al., 2013A).

In addition they highlighted that the saturation of the process zone cannot be detected only with temperature measurement, since the temperature reaches the maximum value much earlier as the vapour space the concentration saturation (Fig. 5).

\subsection{Numerical simulation of the VPS process}

As it was discussed in Section 2.2, the harsh environment in the VPS process zone makes the measurements complicated. Most of the researchers of this field agree that the obtained results are usually not enough accurate, the measurements resolution is low and the measurement device perturbs the system considerably. Therefore, the numerical simulation was always a key tool in deeper understanding of this technology. The numerical models of the VPS process can be distinguished into two branch: the simplified process models (describe only with the temperature change of the soldered assembly in order to optimize the process) and the detailed multi-physical models(describe all the physical phenomena during the VPS process in order the deeper understand of the process).

From the simplified process models the first was developed by Leider, 2012. His model based on the simple solution of the Newton's law (Eq. 2) and provided only a not accurate average temperature change of the whole solder assembly during VPS process. Géczy et al., 2013B created a totally new concept on this filed with the introduction of the "filmwise" condensation theory for VPS process. The top and bottom surfaces of the assembly were investigated separately with the Bejan And Gerstmann-Griffith approaches, respectively. Their model based on the calculation of the Nusselt number which was modified according to the 
special features of the VPS process. Although, their results were still "only" the average temperature change of the soldered assembly but the progress was considerable, the results showed very good agreement with the validation measurements. In addition, the necessary calculation time of the model is only some seconds, what makes the model suitable for realtime application.

Multi-physics modelling of the VPS process started in 2012 with the numerical calculation of the vapour space formation in a small batch type oven during the pre-heating (Illés and Géczy, 2012) and during the immersion of the assembly into the process zone (Illés and Géczy, 2012) (these works were related to the work in (Géczy et al., 2013A)). The multi-physics approach of the VPS process is complicated since a lot of different physical phenomena have to take into consideration like, condensation mass transport, condensation energy transport, heat diffusion at the vapour-condensate boundary, heat diffusion at the condensate-solid boundary. The handling these combined transport mechanisms is the most complicated task, since the Partial Differential Equations (PDEs) of the different physical phenomena have different stability and convergence criteria which have to be handled together and the data change between the equations has to be solved in the same time. For this purpose, the numerical conversion of the PDEs was done by Finite Difference Method (FDM) and was solved by explicit Forward Time Central Space (FTCS) algorithm in order to achieve high solving calculation speed and flexible implementation.

The results showed how the evaporated vapour fill the process zone and highlighted the effect of the inhomogeneous heating on the vapour space saturation, namely that the vapour space saturated much earlier nearby the heater elements than other parts (Illés and Géczy, 2012). This result helps the application of Géczy's method for saturation detection (Section 2.2). Fig. 6 shows how the immersed assembly consumes the vapour around itself. For this purpose a new dew point model for the Galden liquid has to be introduced (Illés and Géczy, 2013). Close by the assembly the vapour concentration decreases to the third of the saturated value where the further condensation is stopped due to the reaching of the dew point. This fact proved the important finding that the conducted heat from the vapour space is also considerable during the VPS process and not only the latent heat of condensation. 

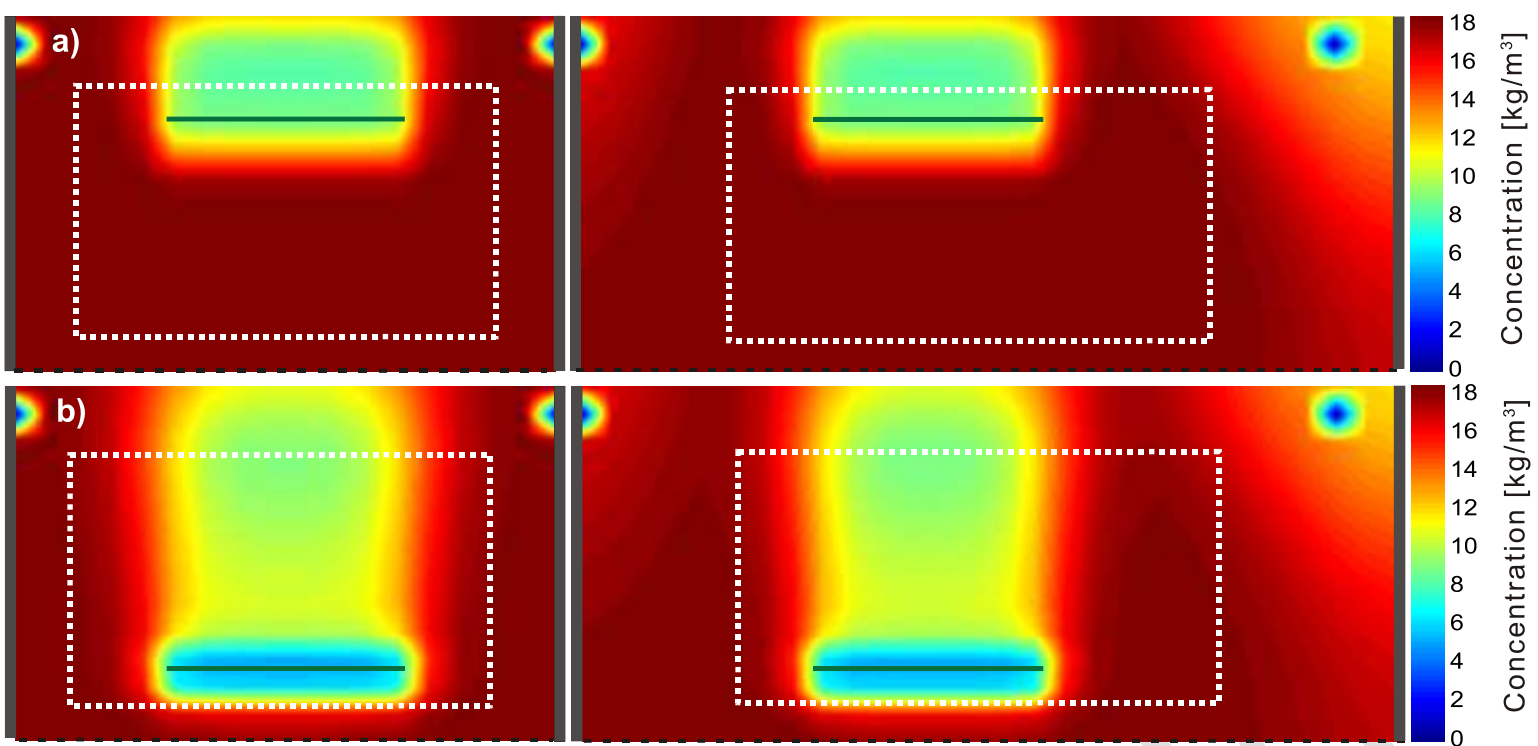

Fig. 6. Vapour distributions along the major axes of the process zone during the immersion of the assembly: a) 1 sec and b) 3 sec (Illés and Géczy, 2013).

Next major step was the modelling of the condensate layer on the assembly. As it was found during the measurements as well, the change of the condensate layer thickness and temperature is essential in the heat transfer of the VPS technology since these parameters determines the heat diffusivity of the condensate layer which determines the HTC. First results about the condensate layer formation during the whole soldering process was published in 2014 (Illés and Géczy, 2014) and this work was supplemented with the inclined case of the assembly (Illés and Géczy, 2016). The models were based on the convective mass transport in the condensate due to the hydrostatic pressure difference and the gravity force and on the conductive and convective energy transport in the condensate.

The results showed that the calculations of the heat transfer are much more accurate with a "dynamic condensate layer" than with a static one (as it was used previously). As thickness of the condensate decreased towards the corners and edges of the assembly, the temperature of the condensate layer increases. The considerable corner effect of the VPS technology can results in even $5-10^{\circ} \mathrm{C}$ temperature difference between the middle and the corners of the PCB (Fig 7 a). Therefore, keepout regions were suggested at edges of the PCB in order to avoid soldering failures (Illés and Géczy, 2014). Furthermore, it was found that the moderate inclination of the assembly $\left(1-10^{\circ}\right)$ decreases condensate layer thickness differences and the temperature differences on the surface of the assembly (Fig. 7 b), thus it considerably improves the uniformity of heat transfer (Illés and Géczy, 2016). Therefore with a moderate inclination of the assembly might reduce the soldering failures during the VPS process 

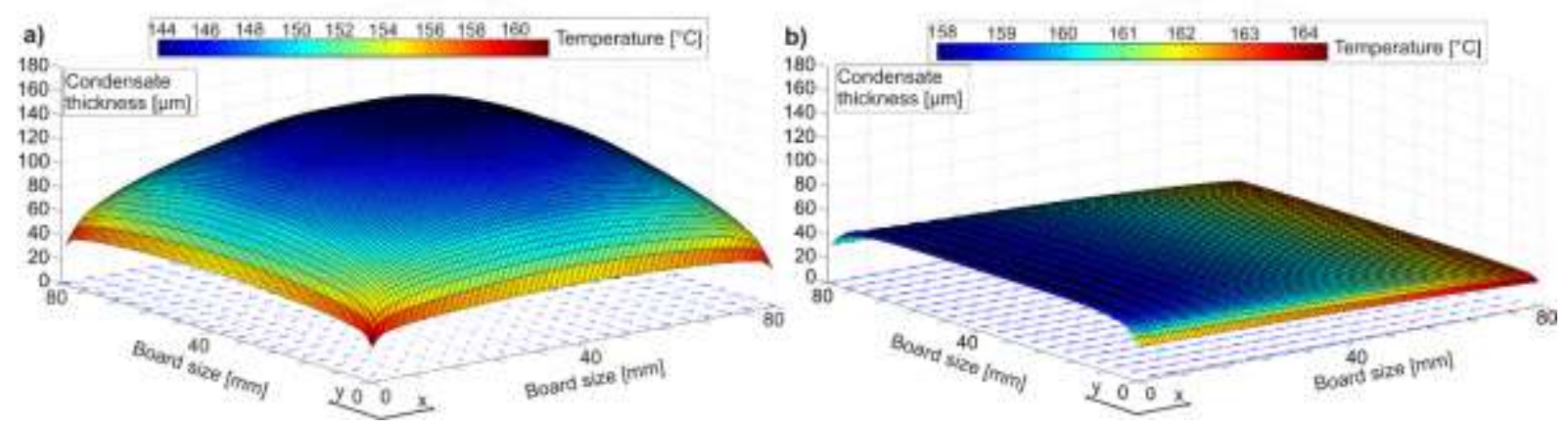

Fig. 7. Condensate layer on the top side at $2 \mathrm{~s}$ : a) inclination angle $0^{\circ} ; \mathrm{b}$ ) inclination angle $10^{\circ}$ (Illés and Géczy, 2016).

The literature contains some results already at the level of discrete components. The author proved that the keepout zones are even more important in the case of large sized components since they can cause congestion of the condensate layer which results in considerable condensate thickness differences between the opposite leads (and solder joints) of the component together with considerable heat transfer differences. This can cause difference in the onset of solder alloy melting between the opposite leads even 2s (Illés et al., 2018A). According to the industrial experiments if the difference in onset of melting is over $0.2-0.3 \mathrm{~s}$, then the probability of component displacement failure increases considerably. The effect of the low pressure generation on the solidification of the solder joint were also examined during the vacuum VPS process (Illés et al., 2018B). It was found that process zone can suffers considerable heat loss on the suction pipe which results in the drop of the solder joints temperature. In the case of thin FR4 PCB $(<1.5 \mathrm{~mm})$ with small components $(<0.5 \mathrm{~mm})$, the solder joints can solidify during the low pressure generation before the voids would be removed from the solder joints (Illés et al., 2018B).

\subsection{Quality and reliability studies of the solder joints prepared by VPS}

As of course in a production technology one of the most important aspects is the quality and reliability of the produced goods, in the given case the quality and reliability of the solder joints. One of the biggest concern about the VPS technology was the possible contamination on the assembly due to the heat transfer liquid, which can enhance such a reliability problems like electrochemical migration. However, the author proved that the residuals from the Galden liquid do not have any effect on the meant time to failure in the case of electrochemical migration (Illés et al., 2014). Dumitru et al., 2014 investigated the adhesion of the copper layer on different PCB materials (FR2, FR4 and CEM) with a micro- scratch tester after VPS process. 
They measured the highest friction force at the CEM substrate, the FR2 and FR4 performed similar values.

The good electrical conductivity and mechanical stability are essential parameters of the solder joints. Since the VPS process is recommended for low-melting temperature solder alloys, Cucu et al. developed a new evaluation method for low-melting temperature solder joints prepared by VPS technology. During the shear force and electrical conductivity measurements the solder joints are heated up to different elevated temperatures (as simulating a real environment in an automobile), in order to study the behavior of the solder joints (Cucu et al., 2014). With the previous method, Branzei et al., 2017 studied the relationship between the heat transfer and the mechanical strength of the solder joints prepared from low-melting temperature solder alloys. Their results are a new milestone for redesign the thermal profiles in VPS technology for the low-melting temperature solder alloys, in order to reduce energy consumption and the soldering failures.

Another important aspect is the microstructure of the solder joint which has serious effect on quality and reliability. Krammer, 2014 compared the intermetallic layer (IML) of a traditional lead-free (SAC305) solder joints prepared with infrared (IR) and VPS technology. He used thermal shock test for aging of the solder joints. The results showed that the different heat transfer at the different soldering technologies caused different IML development (Fig. 8).

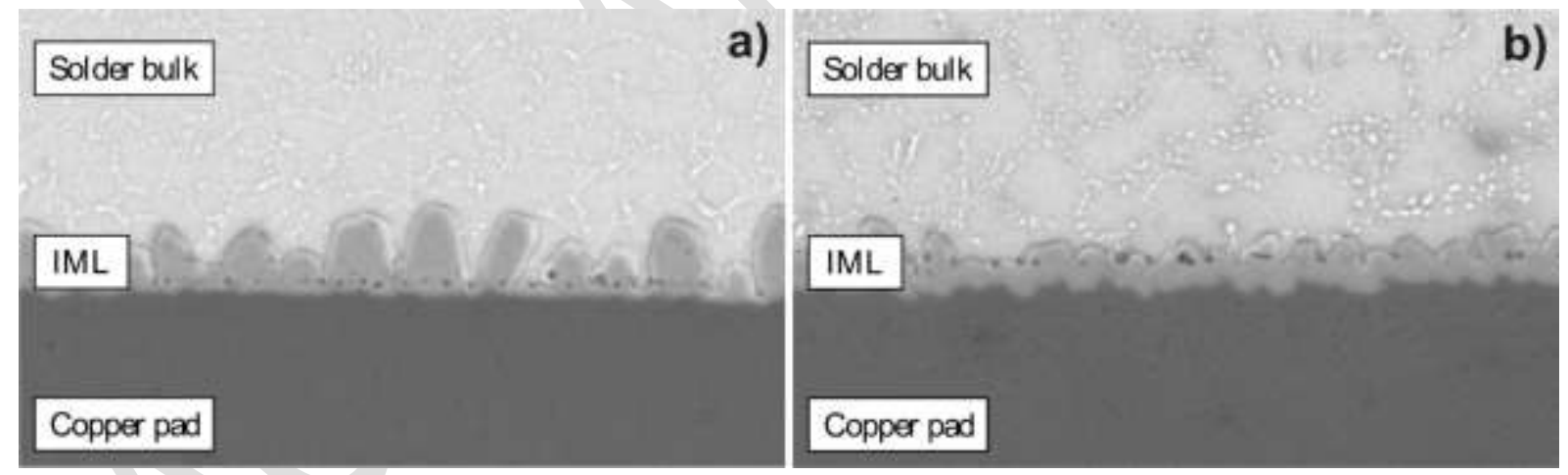

Fig. 8. The IML of solder joints: a) IR reflow, b) VPS (Krammer, 2014).

The IML of the IR solder joints was scallop type, while the IML of VPS solder joints was layerlike; with even surface, what might be caused by the more uniform heating with and lower peak temperature of the VPS process. Furthermore during the thermal shock test, the development of the IML layer was much slower in the solder joints which were prepared by VPS technology than in the solder joints prepared by IR reflow soldering. The longer life-time of the VPS solder joints supports the applicability of VPS technology for high-reliability circuits. Liu et al. compared the mechanical properties of solder joints prepared from special solder alloys $\mathrm{AgCu} / 62 \mathrm{Sn} 36 \mathrm{~Pb} 2 \mathrm{Ag} / \mathrm{CuBe}$ and $\mathrm{AgCu} / 63 \mathrm{Sn} 37 \mathrm{~Pb} / \mathrm{CuBe}$ on FR4 substrates by VPS process (Liu 
et al., 2015). They found that by optimizing the parameters of VPS technology, fast dissolution of $\mathrm{Ag}$ from the structural $\mathrm{AgCu}$ pads and formation of big plate-like or blocky $\mathrm{Ag}_{3} \mathrm{Sn}$ in the joints can be depressed, which can improve the mechanical stability of the solder joints.

The issue of voiding was deeply investigated in the case of VPS technology and this type of soldering problem was found to be more serious than in the case of conventional soldering technologies. Synkiewicz et al., 2014 investigated the effect of the solder alloys $(63 \mathrm{Sn} 37 \mathrm{~Pb}$ $(\mathrm{PbSn})$ and $96 \mathrm{Sn} 3.5 \mathrm{Ag} 0.5 \mathrm{Cu}(\mathrm{SAC} 305))$ on the voiding and they found that alloy composition has minor impact on void formation. The tendency for a different arrangement of voids in a solder joints depends on much more the size of the SMD component and with this on the amount of the solder paste. On year later they investigated the void suppressing efficiency of the vacuum VPS technology and found that with vacuum application $31 \%$ less void was formed in the SAC solder joints than without vacuum (Synkiewicz et al., 2015). They stated that the vacuum decreases the number of the voids, and significantly decreases the diameter of voids, which is important during the assembly of large sized components where the area of the solder pad is relatively large. The author investigated efficiency of the void separation of the vacuum VPS technology in the case of different substrates (Illés et al., 2017B). It was proven experimentally that the heat capacity of the substrate material has serious effect on the efficiency of the void elimination. In the case of thinner substrates with low heat capacity, the efficiency of the void separation decreases considerably, since the process zone loses some heat during the vacuum curing which can results the early solidification of the solder joints.

The void content of the solder joints effects on the mechanical, thermal and electrical parameters of the solder joints. Skwarek et. al compared the mechanical stability of SAC solder joints on DBC substrates created by convection reflow soldering, simple VPS and vacuum VPS technologies (Skwarek et al., 2017). They found $15 \%$ higher shear strength of the solder joints in the case of vacuum VPS and than at the solder joints prepared by convection reflow soldering. However the shear strength was $40 \%$ lower without the vacuum setting. Computed tomography and SEM analysis proved that the smallest sizes and amounts of voids were in the solder joints prepared with vacuum VPS, while the largest sizes and highest numbers of voids were in the solder joint created by simple VPS process (Fig. 9). 

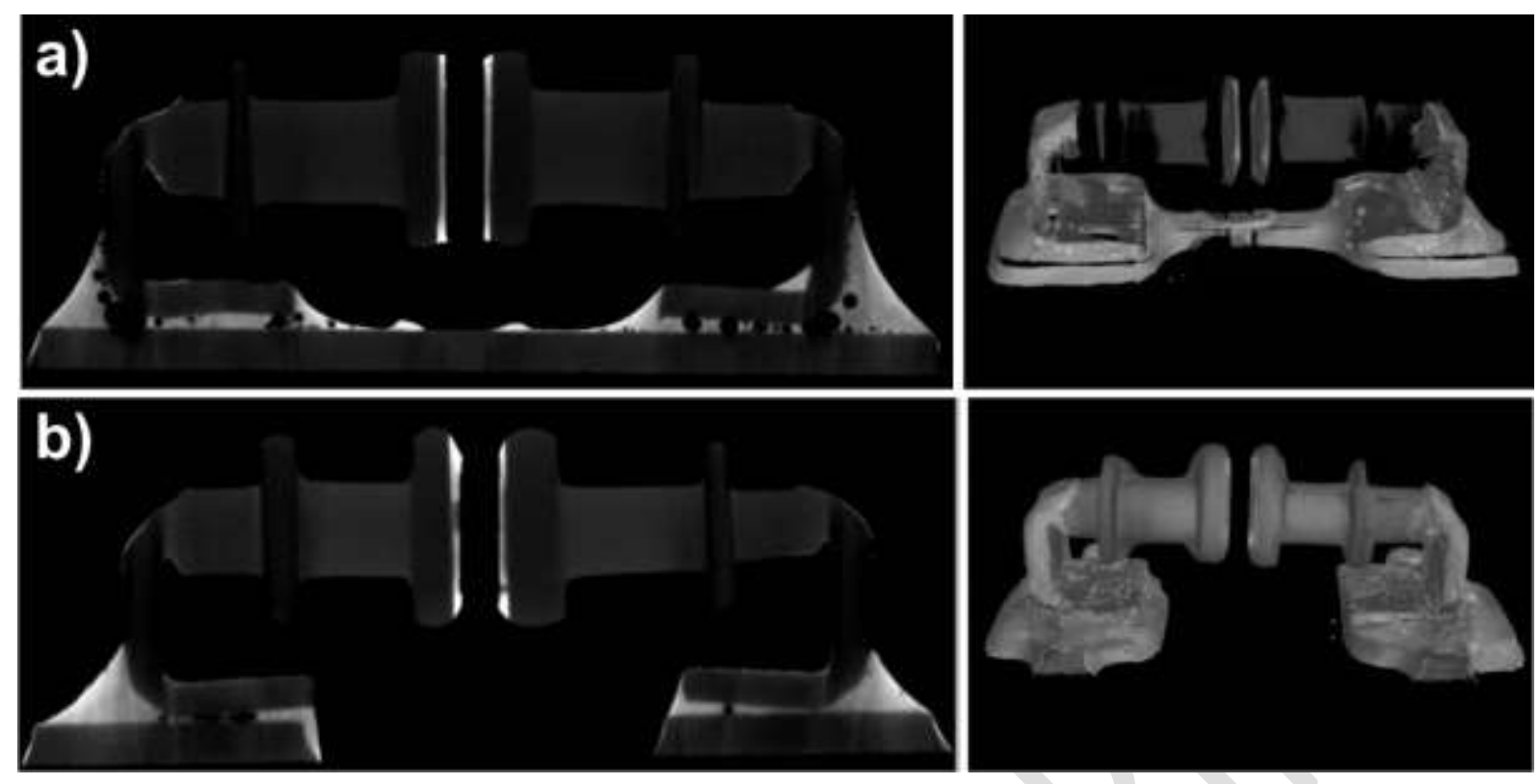

Fig. 8. 2D and 3D computed tomography pictures of the sample: a) made by convection reflow soldering; b) made by vacuum VPS (Skwarek et al., 2017).

Dziurdzia et al., 2018 did statistically comparison about the void content in solder joints of LED and BGA components prepared by vacuum VPS and convection reflow soldering. Their results also supported the previous findings, that the vacuum option during the VPS process could produce even less voids than the convection reflow soldering. Górecki et al., 2018 also showed that the thermal resistance of soldered LED modules are $15 \%$ lower in the case of vacuum VPS soldering than in the case of convection reflow soldering which is also related to the lower void content in the case of vacuum VPS process.

\section{Conclusions}

A review of the recent results and developments of the VPS technology was reported. It was concluded that up to now, the reflow soldering with VPS technology becomes a real alternative of the conventional reflow soldering technologies. The most important findings are the following:

- The working principle of the VPS technology allows the best thermal management in soldering, expect the very fast heat transfer. Good attempts to reduce of the HTC values are already existing (like soft VPS or real-time power control) but further researches are necessary.

- The harsh environment and the hermetically closed process zone usually inhibits the enough fine and accurate measurements, therefore the numerical simulation is an 
essential tool for understanding the physical phenomena of this technology and for the process optimization.

- Generally, the quality and reliability of the solder joints prepared by VPS technology is not worse than the quality and reliability of the solder joints prepared by conventional reflow soldering technologies. Some parameters - like the mechanical stability - is even better.

- The increased void formation is still the most serious problem of the VPS technology. The application of the vacuum option during VPS technology can considerably depress the voids formation. However, the heat loss of the process zone during the vacuum curing can cause the early solidification of the solder joints in the case of thin substrates. Therefore further researches are necessary about the voiding problem during the VPS technology.

\section{Acknowledgment}

The research reported in this paper was supported by the Higher Education Excellence Program of the Ministry of Human Capacities in the frame of Nanotechnology and Material Science research area of Budapest University of Technology and Economics (BME FIKPNAT).

\section{REFERENCES}

Bátorfi, R., Szőke, P., Oláh, Z., Géczy, A., Ruszinkó, M., Illyefalvi-Vitéz, Z. (2010) "Bumping Technologies of Fine-Pitch BGA Components", in proceedings of 33rd International Spring Seminar on Electronics Technology (ISSE), IEEE, pp. 229-234.

Bielick, J., Chapman, B., Ferrill, M., Fisher, M., Isaacs, P., Kobeda, E., Lewis, T. (2010), "High Thermal Mass, Very High Lead Count SMT Connector Rework Process: Process and Problem Resolution", in proceedings of SMTA Pan Pacific Symposium.

Bielick, J. (2010), "High thermal mass, very high lead count SMT connector rework process: rigorous testing found local vapor phase clearly superior to alternative processes." Printed Circuit Design \& Fabrication, Vol. 27. pp. 40-44.

Branzei, M., Vladescu, M., Plotog, I, Cucu, T. (2017), “Comparative Shear Tests of Two Low Melting Point Solder Pastes Relating to their Thermal Diffusivity", in Pproceedings of 40th International Spring Seminar on Electronics Technology (ISSE), IEEE, Sofia, Bulgaria, pp 1.-6.

Chang, F.L., Hung, Y.M. (2017), "Dielectric liquid pumping flow in optimally operated micro heat pipes”, International Journal of Heat Mass Transfer, Vol. 108, pp. 257-270. 
Coada, D. (2009), "PoP (package on package) and vapor phase technology", Global SMT \& Packaging, Vol.9.

Coombs C.F. Freedman, G.M. (2008), "Vapor-Phase Reflow Soldering", Printed Circuits Handbook (6th ed.), Chapter 47.6, McGraw-Hill, pp. 47.42-47.43.

Cucu, T.C, Plotog, I., Branzei, M. (2014), "Mechanical tests regarding low-temperature leadfree solder pastes application in automotive electronics", in proceedings of $20^{\text {th }}$ International Symposium for Design and Technology in Electronic Packaging (SIITME), IEEE, Bucharest, Romania, pp. 63-68.

Duck, A, Zabel, C. (2010), "Vapour Phase Reflow - Profiling for Lead Free Alloys.", in Proceedings of International Conference on Soldering and Reliability, SMTA, Toronto, Ontario.

Dumitru, G.A, Tudor, A., Chisiu, G., Plotog, I. (2014), "Mechanical Characteristics of Electronic Printed Circuit Obtained by the Vapour Phase Soldering Process", Applied Mechanics and Materials, Vol. 658 pp. 71-76.

Dušek, K., Bušek, D., Plaček, M., Géczy, A., Krammer, O., Illés, B. (2018), “Influence of vapor phase soldering fluid Galden on wetting forces (tombstone effect)", Journal of Materials Processing Technology, Vol. 251 pp. 20-25.

Dziurdzia, B., Sobolewski, M., Mikolajek, J. (2018), "Convection vs vapour phase reflow in LED and BGA assembly”, Soldering \& Surface Mount Technology Vol. 30, pp. 87-99.

Fazekas, L., Nagy, D., Géczy, A., Busek, D. (2016), "Investigations on Heat Transfer with Different PCB Substrates during Vapour Phase Soldering”, in proceedings of 22th International Symposium for Design and Technology in Electronic Packaging (SIITME), IEEE, pp. 48-54.

Géczy, A., Bátorfi, R., Gál, L., Illyefalvi-Vitez, Z., Szőke, P. (2010), "Evaluating Vapor Phase Soldering for Fine Pitch BGA", in proceedings of 33rd International Spring Seminar on Electronics Technology, ISSE, pp. 482-487.

Géczy A., Léner V., Hajdu I., Illyefalvi-Vitéz Z. (2011), "Low Temperature Soldering on Biopolymer (PLA) Printed Wiring Board Substrate", in proceedings of 34th International Spring Seminar on Electronics Technology (ISSE), IEEE, Tatranska Lomnica, Slovakia, pp. 57-62.

Géczy, A., Illyefalvi-Vitéz, Z., Szőke, P. (2012), "Investigations on Vapor Phase Soldering Process in an Experimental Soldering Station”, Micro and Nanosystems, Vol. 2 pp. 170177. 
Géczy, A., Illés, B., Péter, Z., Illyefalvi-Vitéz, Z. (2013A), “Characterization of Vapour Phase Soldering Process Zone with Pressure Measurements", Soldering \& Surface Mount Technology, Vol. 25, pp. 99-106.

Géczy, A., Illés, B., Illyefalvi-Vitéz, Z. (2013B), “Modeling Method of Heat Transfer During Vapour Phase Soldering Based on Filmwise Condensation Theory", International Journal of Heat Mass Transfer Vol. 67 pp. 1145-1150.

Géczy, A. (2014), "Investigations into the Process of Vapour Phase Soldering", PhD dissertation, Budapest University of Technology and Economics, p. 114.

Géczy, A., Kvanduk, B., Illés, B., Harsányi, G. (2016), "Comparative Study on Proper Thermocouple Attachment for Vapour Phase Soldering Profiling, Soldering \& Surface Mount Technology, Vol. 28, pp. 7-12.

Géczy A. (2017), "Investigating heat transfer coefficient differences on printed circuit boards during vapour phase reflow soldering", International Journal of Heat and Mass Transfer, Vol. 109, pp. 167-174.

Géczy, A., Nagy, A., Illés, B., György, Z., Busek, D. (2017), "Investigating the effect of large SMD components on heating during vapour phase soldering", in Proceedings of 23th International Symposium for Design and Technology in Electronic Packaging (SIITME), IEEE, pp. 44-49.

Górecki, K., Dziurdzia, B., Ptak, P. (2018), "The influence of a soldering manner on thermal properties of LED modules", Soldering \& Surface Mount Technology, Vol. 30, pp. 81-86.

Huang, J., Zhang, J., Wang, L. (2015), "Review of vapor condensation heat and mass transfer in the presence of non-condensable gas", Applied Thermal Engineering, Vol. 89 pp. 469 484.

Illés, B., Géczy, A. (2012), "Multi-Physics Modelling of a Vapour Phase Soldering (VPS) System", Applied Thermal Engineering, Vol. 48, pp. 54-62.

Illés, B., Géczy A. (2013), "Investigating the dynamic changes of the vapour concentration in a vapour phase soldering oven by simplified condensation modeling", Applied Thermal Engineering, Vol. 59, pp. 94-100.

Illés, B., Géczy, A. (2014), "Numerical Simulation of Condensate Layer Formation During Vapour Phase Soldering”, Applied Thermal Engineering, Vol. 70, pp. 421-429.

Illés, B., Medgyes, B., Horváth, A. (2014), "Electrochemical Migration Behaviour of Surface Finishes after Vapour Phase Reflow Soldering”, in proceedings of 20th International Symposium for Design and Technology in Electronic Packaging (SIITME), IEEE, pp. 253-257. 
Illés, B., Bakó, I. (2014), "Numerical study of the gas flow velocity space in convection reflow oven”, International Journal of Heat and Mass Transfer Vol. 70, pp. 195-191.

Illés, B., Géczy, A., Skwarek, A., Busek, D., (2016), "Effects of substrate thermal properties on the heat transfer coefficient of vapour phase soldering", International Journal of Heat and Mass Transfer, Vol. 101, pp. 69-75.

Illés, B., Géczy, A. (2016), "Investigating the heat transfer on the top side of inclined printed circuit boards during vapour phase soldering", Applied Thermal Engineering, Vol. 103, pp. 1398-1407.

Illés, B., Skwarek, A., Géczy, A., Krammer, O., Bušek D. (2017A), "Numerical modelling of the heat and mass transport processes in a Vacuum Vapour Phase Soldering System", International Journal of Heat Mass Transfer, Vol. 114 pp. 613-620.

Illés, B., Skwarek, A. Géczy, A., Szwagierczak, D., Witek, K. (2017B), "Void Separation Efficiency of Vacuum VPS technology on FR4 and LTCC Substrates", in proceedings of 23th International Symposium for Design and Technology in Electronic Packaging (SIITME), IEEE, pp. 68-72.

Illés, B., Géczy, A., Krammer, O., Dušek, K., Bušek, D. (2018A), "Numerical investigation on the effect of condensate layer formation around large-size components during vapour phase soldering”, International Journal of Heat Mass Transfer, Vol. 125, pp. 202-209.

Illés, B., Skwarek, A., Géczy, A., Jakab, L., Bušek, D., Dušek, K. (2018B), "Effect of the Vapour Concentration Decrease on the Solder Joints Temperature in a Vacuum Vapour Phase Soldering System", Soldering \& Surface Mount Technology, Vol. 30 pp. 66-73.

Illyefalvi-Vitéz, Z., Géczy, A., Szőke, P., Bátorfi, R., Törzsök I. (2010A), "Experimental investigations on the vapor phase soldering process", in proceedings of 16th International Symposium for Design and Technology in Electronic Packaging (SIITME), IEEE, pp. 2528.

Illyefalvi-Vitéz, Z., Géczy, A., Bátorfi, R., Szőke, P. (2010B), "Analysis of Vapor Phase Soldering in Comparison with Conventional Soldering Technologies", proceedings of 3rd Electronic System-Integration Technology Conference (ESTC), IEEE.

Kaew-On, J., Naphattharanun, N., Binmud, R., Wongwises, S. (2016), “Condensation heat transfer characteristics of R134a flowing inside mini circular and flattened tubes", International Journal of Heat Mass Transfer, Vol. 102, pp. 86-97.

Krammer, O. (2014), “Comparing the reliability and intermetallic layer of solder joints prepared with infrared and vapour phase soldering", Soldering \& Surface Mount Technology, Vol. 26, pp. 214-222. 
Lee, K.W., Earmme, Y.Y. (1998), "Effect of geometric parameters on popcorn cracking in plastic packages during VPS process", Finite Elements in Analysis and Design, Vol. 30, pp. 81-96.

Lee, N.-C. (2002), "Reflow Soldering Processes and Troubleshooting: SMT, BGA, CSP and Flip Chip Technologies", BH Newnes, pp 4/77-4/80.

Leicht H., Thumm A. (2008), “Today's Vapor Phase Soldering - An Optimized Reflow Technology for Lead Free Soldering”, in proceedings of SMTAI, Orlando.

Leider W. (2002), "Dampfphasenlöten - Grundlagen und praktische Anwendung", Eugen G. Leuze Verlag, Bad Saulgau, Germany, pp. 31-39.

Liu, W., An, R., Ding, Y., Wang, C.-Q., Tian, Y.-H, Shen, K. (2015), "Microstructure and properties of $\mathrm{AgCu} / 2 \mathrm{wt} \% \mathrm{Ag}$-added $\mathrm{Sn}-\mathrm{Pb}$ solder/CuBe joints fabricated by vapor phase soldering”, Rare Metals, DOI 10.1007/s12598-015-0545-y

Livovsky, L., Pietrikova, A. Durisin, J. (2008), "Monitoring of the Temperature Profile of Vapour Phase Reflow Soldering", in proceedings of 31st International Spring Seminar on Electronics Technology (ISSE), IEEE, pp. 667-669.

Livovsky, L., Pietrikova, A. (2017), "Real-time profiling of reflow process in VPS chamber”, Soldering \& Surface Mount Technology, Vol. 29, pp. 42-48.

Naldi, C., Zanchini, E. (2017), "Dynamic simulation during summer of a reversible multifunction heat pump with condensation-heat recovery", Applied Thermal Engineering, Vol. 116, pp. 126-133.

Nielsen, R.P., Valsecchi, R., Strandgaard, M., Maschietti M. (2015), "Experimental study on fluid phase equilibria of hydroxyl-terminated perfluoropolyether oligomers and supercritical carbon dioxide”, Journal of Superstitious Fluids, Vol. 101, pp. 124-130.

Nowottnick, M., Diehm, R. (2007), "Soldering Technology for 3D PCB Assemblies with Microwave Heating", in proceedings of ISIE International Symposium on Industrial Electronics, IEEE, pp. 3273-3277.

Pfahl R.C., Ammann H.H. (1975), "Method for Soldering, Fusing or Bracing”, US Patent 3,866,307.

Plotog, I., Codreanu, N., Svasta, P., Cucu, T., Turcu, C., Vărzaru, G., Lazár G., Bătucă, A. (2008),"Investigations on Assembling of Electronic Packages onto Glass Substrates using Lead-free Technology", in proceedings of 31st International Spring Seminar on Electronics Technology (ISSE), IEEE, pp. 409-413.

Skwarek, A., Synkiewicz, B.K., Kulawik, J., Guzdek, P., Witek, K., Tarasiuk, J. (2015), “High temperature thermogenerators made on DBC substrate using vapour phase soldering", Soldering \& Surface Mount Technology, Vol. 27 pp. 125-128. 
Skwarek, A., Illés, B., Synkiewicz, B., Wroński, S., Tarasiuk, J., Witek, K. (2017), "Characterization of solder joints made with VPS on DBC substrate", Journal of Materials Science: Materials in Electronics, Vol. 28, pp. 1769-1776.

Sprovieri, J. (2012), “Getting the Vapors”, SMT Magazine.

Synkiewicz B.K., Skwarek A., Witek K. (2014), "Voids investigation in solder joints performed with vapour phase soldering (VPS)", Soldering \& Surface Mount Technology, Vol. 26 pp. $8-11$.

Synkiewicz, B., Skwarek, A., Witek K. (2015), "Vapour phase soldering used for quality improvement of semiconductor thermogenerators (TEGs) assembly", Material Science in Semiconductor Processing, Vol. 38, pp. 346-351.

Vianco, P.T. (1999), "Soldering Handbook (3rd Ed)”, American Welding Society: Miami, FL, pp. $9-11$

Villain, J., Beschomer, M., Hacke, H. J., Brabetz, B., Zapf, J. (2000), “Formation, Distribution and Failure Effects of Voids in Vapor-Phase Soldered Small Solder Volumes", in proceedings of International Symposium on Advanced Packaging Material Processes, Properties and Interfaces, Chateau Elan, Braselton, Georgia, pp. 141-144.

Wenger, G.M., Mahajan, R.L., "Die Technology des Löten in der Dampfphase”, Fluorinert Nachrichten, Vol. 3.

Zabel C., Duck A. (2009), "Vapourphase vacuum-soldering. A new process technology opens tremendous production capabilities when reflow-soldering.", in proceedings of SMTA International Conference, SMTA, San Diego, California. 